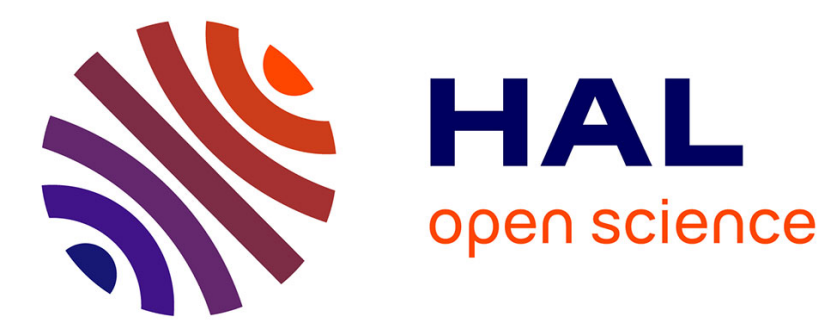

\title{
Specific roles of phosphatidylglycerols in hosts and microbes
}

Isabelle Dugail, Brandon D. Kayser, Marie Lhomme

\section{To cite this version:}

Isabelle Dugail, Brandon D. Kayser, Marie Lhomme. Specific roles of phosphatidylglycerols in hosts and microbes. Biochimie, 2017, 10.1016/j.biochi.2017.05.005 . hal-01521064

\section{HAL Id: hal-01521064 \\ https://hal.sorbonne-universite.fr/hal-01521064}

Submitted on 19 May 2017

HAL is a multi-disciplinary open access archive for the deposit and dissemination of scientific research documents, whether they are published or not. The documents may come from teaching and research institutions in France or abroad, or from public or private research centers.
L'archive ouverte pluridisciplinaire HAL, est destinée au dépôt et à la diffusion de documents scientifiques de niveau recherche, publiés ou non, émanant des établissements d'enseignement et de recherche français ou étrangers, des laboratoires publics ou privés. 


\title{
Specific roles of Phosphatidylglycerols in Hosts and Microbes
}

\author{
Isabelle Dugail ${ }^{1,2}$, Brandon D. Kayser ${ }^{1,3}$, Marie Lhomme ${ }^{3}$.
}

${ }^{1}$ INSERM, UMR_S 1166, Nutriomics Team, Paris 75013, France;

${ }^{2}$ Sorbonne Universités, UPMC University Paris 06, UMR_S 1166, Nutriomics Team, Paris, France

${ }^{3}$ ICAN, Institute of Cardiometabolism and Nutrition, Paris, 75013-France;

Faculté de médecine Pitie-Salpetriere, 91 bd de l'hopital, 75013 Paris France.

Correspondence to : isabelle.dugail@inserm.fr

\begin{abstract}
Summary :
Phosphatidylglycerols (PGS) are specific phospholipids bearing negatively charged polar headgroups. Although recognized for long as a major lipid component of membranes in bacteria, it is considered a minor lipid in higher eukaryotes, due to its low abundance in biological fluids or tissues. However, new sensitive lipidomic approaches now provide tools for accurate quantification of $P G s$ in biological samples, and this is likely to uncover new roles for these phospholipids in the near future. This paper reviews our present knowledge in $P G$ function, from studies in microbes and eukaryotic cells, and gathers in one place a diverse range of information spread across many fields. The physical properties of PGs, their biological distribution and molecular functions make them potential actors in host-microbe interaction.
\end{abstract}

1. Introduction

An assortment of different headgroups are found in phospholipids, mainly choline, ethanolamine, serine, inositols and glycerol, that define 6 distinct structural classes, plus phosphatidic acids in which no head group is added. The diversity of polar head groups is thought to contribute optimal surface charge of membranes or lipid particles so that zwitterionic headgroups balance phospholipids containing acidic headgroups. Besides electrostatic balance, it is likely that some advantage is linked to headgroup diversity versus "one fits all", that can override the cost for stringent regulation synthesis of phospholipids with different headgroup moieties. Especially, integral membrane proteins might require diverse phospholipid environment to adopt correct topology in membranes. Furthermore, specific properties linked to particular phospholipids can exist, such as phosphatidylinositol binding domains in proteins with crucial importance in protein/membrane interaction. With 
recently developed high throughput mass-spectrometry-based lipidomics technologies, detailed evaluation of lipid diversity at a molecular scale has become accessible, and is expected to provide new paradigms in understanding lipid diversity. PG levels rise in obesityassociated fatty liver disease (1), type-II diabetes (2), breast cancer (3) and perhaps other still to be defined conditions. In the present paper, we will concentrate on specific features of PGs to review our present knowledge on specific roles and properties of this unique phospholipid class (figure 1).

\section{General principles in PGs distribution and abundance}

PGs are negatively charged phospholipids found ubiquitously, but a key feature is their differential abundance among organisms. According to biochemistry text books, PGs are found as major phospholipid components of cell membranes in bacteria, representing 20-25\% of total lipid phosphorus in most Gram-negative bacteria with a double (outer and inner) phospholipid envelop, where it is restricted within the inner membrane. In Gram-positive strains (with a single phospholipid bilayer coated with peptidoeglycans) it can be as high as $60 \%$ and even found as the major phospholipid besides sugar derivatives of diacylglycerol. In plants, PGs are major constituents of the leaves representing approximately $20 \%$ of total lipid phosphorus, but is less abundant in fruits, roots and tubers. It is found as the only glycerophospholipid in green alguae. In contrast, PG is a minor phospholipid component in mammals, found at only trace amounts in tissues and fluids except in lung surfactant. In higher eukaryotes it serves mainly as the precursor of mithochondria-specific lipids such as cardiolipin, a diphosphatidyl glycerol molecule structure with 4 fatty acid chains. PG also serves as an intermediate in the synthesis of bis(monoacylglycero)phosphate or BMP, a lipid found enriched in the endolysosomal compartment. Overall, a striking feature of PG biology is its highly variable distribution and abundance in different organisms, from a quasi exclusive glycerophospholipid with structural roles in prokaryotic membranes to trace amounts and highly compartimented distribution in higher organisms.

\section{PG analysis using Liquid Chromatography-Electro Spray Ionisation-Mass Spectrometry (LC-ESI-MS/MS)}

PGs, as all glycerophospholipids are amphiphilic, and their extraction from biological fluids is therefore achieved by combination of relatively polar (such as methanol) and apolar solvents (such as chloroform) initially introduced by Folch et al., and adapted by Bligh and Dyer to obtain a single extraction phase chloroform/methanol/water (1:2:0.8). At neutral $\mathrm{pH}$, PG is in the anionic form, so that mild acidification of the extraction solvent allows the protonation of PG lipids and a better extraction yield. The modified Bligh and Dyer method developed by Ivanova et al. with mild acidification $(0.1 \mathrm{~N} \mathrm{HCl}$ :methanol (1:1)) of the methanol is therefore very efficient for acidic lipids such as PG (4). As for all other glycerolipids, PGs polarity allows their detection using electrospray ionization, but the fast ESI-MS/MS shotgun approach from crude extracts is however not appropriate for minor lipids such as PG whose signal gets easily suppressed by more abundant lipids in the ESI source. PG analysis using MS/MS therefore requires prior separation by liquid chromatography, that can be achieved with hydrophobicity-based separation (chain length and unsaturation) using reversed-phase LC columns (5) or polarity-based separation depending on 
headgroup using normal phase columns (4). The latter chromatography uses however hazardous apolar solvents such as chloroform or hexane and tends to get replaced by hydrophilic interaction chromatography (HILIC), which allows a normal-phase type separation using reversed-phase type solvents at a relatively fast speed with the development of core-shell technology (6). PG lipids are either analysed in positive ESI-MS/MS mode using the specific polar headgroup neutral loss m/z189 (ammonium adduct of the glycerophosphate moiety) or in the complementary negative ESI-MS/MS mode using the headgroup product ion scan (mz 153) or the fatty acyl chains product ion scan. For specific PG quantification, notably in cell and tissue, positive mode should be preferred as it has a distinct fragmentation pattern from its structural isomer bis(monoacylglycero)phosphate (BMP) (7). Lipid chain elucidation of total PG and BMP is obtained in negative mode. Examples of relative fatty acid composition of PGs in mammalian host serum or Lactobacillus pellets are shown in figure 2, highlighting diversity in PG composition.

4. PG synthesis in microbes and hosts.

\subsection{Canonical PG synthesis pathway (figure 3)}

The pathway for PG synthesis is common in bacteria and higher mammals, elucidated by Kennedy in the 60s $(8 ; 9)$. PG synthesis initiates from the common phospholipid precursor Cytidine Diphosphate Diacylglycerol (CDP-DAG), produced by the CDP-DAG synthase (Cds) also called Phosphatidate Cytidylyltransferase. CDP-DAG is then used by Phosphatidylglycerol synthase (PgsA in Escherichia coli), the first committed enzyme in the PG pathway $(10 ; 11 ; 11)$. Bacterial pgsA and eukaryotic homologues PGS1 $(12 ; 13)$ encode the enzymes that displace CDP by glycerol-phosphate to provide PG-phosphate, which is further dephosphorylated by a phosphatase to form PG. There are three pgp genes in the E. coli genome ( $p g p A, p g p B$ and $p g p C$ ), perhaps not all to serve exclusively for PG phosphate hydrolysis (14). In eukaryotes, multiple PG phosphatase genes also exist $(15 ; 16)$, and enzymatic activity has been detected in mitochondria matrix (17). Whether PG synthesis is essential for bacteria has been debated for some time (18-20). Requirement might depend on the quantitative importance of $\mathrm{PG}$ relative to other membrane lipids in microbial species. Indeed, more severe consequence of abrogation of PG synthesis is expected in bacteria with higher abundance of PG in their membranes $(21 ; 22)$. However, it is difficult to decipher the contribution of other PG-derived products, that might also play important roles in growth. In eukaryotes, PG biosynthesis reside predominantly in the mitochondria, PG-phosphate synthase is a component of the inner mitochondrial membrane (23).

\subsection{Cardiolipin}

Although PG mainly serves a primary structural component of prokaryotic membranes, it is also a required precursor in the synthesis of cardiolipin, which is found at variable amounts in Gram-positive and Gram-negative cell envelops. Three different genes are identified as cardiolipin synthases, named $c l s A / B / C$. In E.coli, the ClsA protein aggregates two PG molecules for cardiolipin formation (24). Some evidences indicate that the other cardiolipin synthases ClsB/ClsC can use PG but also other phospholipid substrates (25). Further, it was reported recently that $\mathrm{ClsB}$ is involved in a new alternative pathway for PG synthesis in $E$. coli, using PE and glycerol-3-phosphate as subtrates (26). Thus, cardiolipin formation is 
tightly connected to both PG and PE phospholipids. In eukaryotes, the synthesis of cardiolipin slightly differs from prokaryotes. In E. coli, Staphylococcus aureus or Lactobacillus planturum, two molecules of PG are condensed, while in mitochondria from liver and Saccharornyces cerevisiae, the prefered substrates are PG and CDP-DAG (27-29). S. aureus express two genes for cardiolipin synthesis, a stress inducible $c l s 1$ and a constitutive $c l s 2$ (30). Their respective contributions in PG/cardiolipin homeostasis is still unknown. Overall, as noticed above, several steps in PG/cardiolipin pathway are assigned multiple genes which may not have redundant functions. Their respective roles in bacterial growth, either in standard laboratory conditions or in "real life" with highly diverse environments still awaits better understanding.

\subsection{BMP}

BMP or bis(monoacylglycero)phosphate is a structural isomer of PG, with one acyl chain linked to each of its glycerol moieties. BMP is thought to be derived from PG since cells deficient in PG synthesis have reduced ability to produce this lipid (31). Remarkably, BMP was reported to date only in eukaryotes, with a strict endosome /lysosomes distribution, and it is still largely unknown how BMP is produced and transported to endo-lysosomes. It remains negatively charged within the acidic environment of lysosomes, and thus might be important in degradative function as well as in preservation of lysosome membrane integrity (32).

\subsection{Aminoacyl PGs}

Bacterial PG phospholipids can also serve as substrates for amino-acyl-phosphatidylglycerol synthases that will link amino acyl residues on the PG head group. As PG aminoacylation changes envelop properties, these are important genes for bacteria to resist antimicrobial compounds (see review (33)). Aminoacyl-tRNAs are used as aminoacid donors in this reaction, and early studies identified the enzyme $\mathrm{MprF}$ (multiple peptide resistance factor) as responsible for the lysylation of membrane PG in S.aureus (33). Lysine is most frequently attached to PGs, but alanine and arginine can also be found, which may affect the spectrum of antimicrobial resistance. Further, analysis of the genomic context of amino-acyl-PG synthase genes in bacteria identified additional families of hydrolase-like sequences in many species. One of these, referred to as AhyD in Enterococcus faecium encodes an amino-acyl-PG hydrolase, which degrades Ala-PG and Lys-PG (34). Thus, amino-acyl-PG synthases and hydrolases may act in concert to fine tune amino-acyl-PGs levels towards adaptation under changing environmental conditions.

\section{Specific roles of PGs among other phospholipids}

Relatively high abundance of PGs in bacterial membranes underlines its importance in membrane properties. Since direct electrostatic interactions between charged species are rather strong, it is likely that PGs, as well as other charged lipids, can function both as membrane stabilizers and destabilizers, and thereby play important roles in controlling membrane/protein interactions (for review see (35). Although few systematic studies examined the properties of PE/PG mixtures in the proportion range of that found in microbes to model bacterial membranes, some biophysical approaches indicate that PGs decrease PE headgroup protrusions into the water phase, and motion of PE headgroup along bilayer 
normal, due to stronger inter-lipid interactions in the mixed bilayer. Thus PG contribution to membrane lipids enhance interface stability, and likely prevents lipid desorption from the membrane. More compact and less dynamic interface structure can also decrease membrane permeability (36). Few specific roles have yet been assigned to PG phospholipids, and most established ones are summarized below. Elucidation of PG contribution is mainly derived from the study of pgsA bacterial mutants with decreased membrane PG abundance, and the controversial question of PG-dependent cell viability (reviewed in (20)) has provided interesting insights into specific PG- regulated process.

\subsection{PGs in extracellular stress sensing and protein secretion across bacterial membranes}

\subsubsection{Lipoprotein maturation}

As initially discovered in eukaryotic cells (37), membrane lipids do not homogenously distribute but can be laterally polarized into domains that produce specific environments for lipid/protein interactions. Cardiolipin, and presumably PGs highly participate in domain formation in E. coli and Bacillus Subtilis and thereby contribute to cell membrane compartimentation, especially to the attachment of peripheral proteins $(38 ; 39)$. In bacteria, lipoproteins generally refer to a group of membrane-associated proteins linked to the outer membrane layer of gram-negative microbes by lipid anchors. Bacterial lipoproteins attach to membrane through a modified acyl group linked to their N-terminal Cys residue. In E. coli, the most abundant lipoprotein, Lpp, is found in the inner leaflet of the outer membrane exposing hydrophilic protein to the periplasm. However, some lipoproteins have been reported to span the outer membrane or expose their protein moiety to the extracellular milieu. Lipoproteins are synthesized in the cytoplasm as precursors and then translocated across the inner membrane mainly through the Sec translocon (40). Overall, studies with pgsA mutants enphasized links to PG and cell lipoprotein synthesis. In E coli lacking PG synthase but with intact Lpp expression, prolipoprotein maturation and trafficking is hampered, which leads to accumulation within the inner membrane and ultimate cell lysis (41). Therefore, PG is considered crucially important in lipoprotein secretion. Mechanistically, it is believed to provide its non-acylated glyceryl moiety to link the $\mathrm{SH}$ group of the N-terminal cysteine residue in the unmodified prolipoprotein, a prerequisite for subsequent acylation of the sn-3 and sn-2 hydroxyls of the glyceryl cysteine to form the diacylglyceryl modified membrane anchored prolipoprotein and later cleavage of the signal peptide (42).

\subsubsection{Lipoteichoic acid synthesis by gram positive bacteria.}

A comparable role of PG in exchanging glycerol phosphate for the synthesis of lipoteichoic acid (LTA) has also been demonstrated (43). LTAs are composed of poly(sn-glycerol-1-P) attached to a glycolipid anchor and contribute to a protective layer surrounding the bacterium. In the prototypical Gram-positive B. subtilis, the length of the polyglycerol-phosphate chain varies from 14 to 33 repeating units. Metabolic labeling experiments identify PG as the source of the glycerol-1-phosphate groups, which means that the biosynthesis of a single LTA molecule requires the utilization of an average of $25 \mathrm{PG}$ molecules.

\subsubsection{Extracellular stress sensing in B. Subtilis}


In $B$. subtilis, all the genes responsible for the synthesis of the lipid species found within the membrane bilayer are dispensable, except $p g s A$, the first gene committed in PG synthesis (see above). Studies with inducible pgsA deletions provided evidence that decreasing membrane PG contents regulated the activity of some Extra Cytoplasmic function (ECF) sigma factors. ECF sigma factors covers a bacterial signalling system specialized in extracellular stress detection, and belong to the large group of sigma factors that are essential components of bacterial RNA polymerase to determine promoter selectivity (reviewed in (44). The substitution of one sigma factor for another can redirect some or all of the RNA polymerase to activate the transcription of genes that would otherwise be silent. Seven ECF sigma factors are found in B. subtillis, they are generally cotranscribed with negative regulators including corresponding transmembrane proteins functioning as anti-sigma factors that bind and inhibit the cognate sigma factor. The sigma factor can be released from its inhibitor upon receiving a stimulus from the environment, thereby coupling cytoplasmic transcriptional response to extracellular signals. In $E$ coli, acute drop in membrane PG content (by removing a synthetic inducer of a $p g s A$ artificial construct) rapidly induced transcriptional activity of sigma $\mathrm{M}$, which is normally known to mediate responses to high salt exposure (45). This might suggest that detection of changes in membrane PG linked to membrane permeability can be an important component in stress response.

\subsection{PG in photosynthesis and electron chain transport}

A detailed review on this topic is published in (46), only salient observations are briefly summarized below. From determination of crystal structures, not only cardiolipin but also PG are integral components of complexes III and IV of the mitochondria of yeast and mammalian cells (47). In plants, PG can be synthesized in the chloroplast, mitochondria and ER, and is the only major phospholipid present in thylakoid membranes, the site of the light-dependent reactions of photosynthesis. In rice thylakoid membrane, the sn-2 position of PGs were found enriched with a specific delta 3-trans-hexadecenoyl, i.e. a 16:1(3t)PG or palmitoyl PG16:0. Surprisingly, such a 16:1(3t) fatty acid was not abundant in any other thylakoid membrane lipid, suggesting a specific role of PG 16:1(3t)(48). Indeed, 16:1(3t) PG was shown to facilitate dimerization of photosystem II (PSII), the first protein complex in the lightdependent reactions of photosynthesis. Particularly one protein in this complex called intrinsic D1 core peptide has high binding affinity for PG which promotes dimerization of the complex. Thin layer chromatography analysis showed that photosystem II dimers contained four times more PG than their monomeric counterparts but with similar levels of phosphatidylcholine (49). PG depletion from thylakoid membrane in PG mutants causes dissociation of extrinsic proteins and PSII dysfunction (50).

\section{$5.3 P G$ in lung surfactant}

The only biological product with significant PG enrichment in higher eukaryotes is the lung surfactant, with more than $10 \%$ of phospholipids as PGs. Lung surfactant occupies the air/water interface of small alveolae where it reduces surface tension and prevents collapse during expiration. Surfactant is produced by type II alveolar cells, stored intracellularly as lamellar bodies, and released extracellularly into alveolar space. Phosphatidyl choline (mainly dipalmitoylphosphatidylcholine, DPPC) is the most abundant phospholipid in surfactant 
(80\%), followed by PG (15\%) and also other lipid components such as cholesterol. Phosphatidylcholine coats the air-water interface of alveoli, with hydrophilic head groups in the water and the hydrophobic tails facing towards the air (51). Surface tension air-water interface tends to make the air bubble smaller by decreasing the surface area of the interface. Surface tension forces also draw fluid from capillaries to the alveolar spaces. By reducing surface tension, surfactant limits fluid accumulation and keeps the airways dry. DPPC has the strongest activity in the pulmonary surfactant mixture, because of high compaction capacity and low bending of the saturated fatty acid chains. However, over pure DPPC, the advantage of a PG/DPPC mixture seems to be linked to lipid monolayer fluidization due to preferentially mono unsaturated fatty acid chains in PG (52). Why PG but not other phospholipids was evolutionary selected still remains elusive. It is estimated that alveolar surfactant has a half life of 5 to 10 hours once secreted. It can be broken down by macrophages and / or reabsorbed into the lamellar structures of type II pneumocytes and recycled back from the alveolar space. This process is believed to occur through specific surfactant proteins especially Surfactant Protein-A (SP-A) which can stimulate receptor mediated, clathrin dependent endocytosis (53).

\subsubsection{PG as a marker of foetal pulmonary development}

Even if the precise role of PG in lung surfactant is still incompletely understood, its presence is a well recognized marker of surfactant production and pulmonary development in the foetus. Therefore, surfactant PG in amniotic fluid has been used for preterm prediction of lung maturation in infants (54), and risks monitoring of Respiratory Distress Syndrome, a life threatening condition in the newborn.

\subsubsection{Surfactant $P G$ in attenuation of pathogen-related inflammatory response}

Numerous macrophages reside in the lung, as a first line of defense against inhaled particles or pathogens. Alveolar macrophages are highly phagocytic, and despite continuous stimulation by inhaled particles and pathogens, they display an anti-inflammatory phenotype that includes specific cytokine responses and reduced oxidant production in response to stimuli, a phenomenon referred to as "alternate activation". Resident alveolar macrophages are bathed in surfactant and have been shown to ingest abundant amounts of it. Therefore, the role of surfactant components in the induction and/or maintenance of an anti-inflammatory phenotype has been of great interest. Some evidence indicate that components of pulmonary surfactant, especially collectins family proteins (to which surfactant proteins belong), might play important roles as modulators of cellular immune activities $(55 ; 56)$. Also, the possibility that phospholipid itself might participate has been less studied. However, some evidence indicate that surfactant is dysfunctional in asthma with diminished PG content, relative loss of PC as well as increasd lysophospholipids (57). It has been suggested that in antigenchallenged patients, secreted phospholipase A2 could participate in surfactant dysfunction, since sPLA2 exhibit preference for PGs over PCs. Regarding a potential role of surfactant PGs in anti-inflammatory response, it was observed that Palmitoyl-OleoylPhosphatidylGlycerol (POPG) alone, added to bronchial epithelial cells in culture inhibited interleukin- 6 and -8 production, as well as the cytopathic effects induced by Rous Sarcoma Virus infection. Administration of POPG to mice, concomitant with viral infection, almost completely eliminated the recovery of virus from the lungs at 3 and 5 days after infection 
(58). PG was shown also to inhibit inflammatory responses induced by lipopolysaccharide through direct interactions with the Toll-like receptor 4 (TLR4) interacting proteins CD14 and MD-2 (59). These findings highlight potential interest of exogenous administration of surfactant PG phospholipids in pulmonary infections, and identify a specific antiinflammatory actions of these lipids. In line with this view that PG might be potent signaling modulators, changes in the affinities of Gai proteins to G-Protein Coupled Receptors (GPCRs) have been recently reported from studies of nanodiscs with various phospholipid compositions

\section{Concluding remarks}

From knowledge acquired in bacteria and eukaryotes regarding multiple functions of PG phospholipids, salient features in modulation of membrane properties have emerged. Of particular interest, it now appears that PG phospholipids could be membrane modulators of signal transduction, particularly in inflammation and GPCR-associated process. Whether those signal modulation properties could exist outside of the assay tube or specific context of a PG enriched environment such as the lung is an important question. PG is present in the plasma, even if found only at micromolar concentrations, therefore considered a minor component. However, advances in mass spectrometry-based lipidomics technologies now make it possible to detect and quantify changes in circulating PG concentrations in health or disease. Many unanswered questions are raised regarding circulating PGs, related to lipids/proteins associations in serum, origin, biological roles, potential target tissues as well as value as new biological markers in disease conditions.

Acknowledgements : Lipidomic core facility of ICAN institute and funding from Horizon 2020 Framework Program (EPoS, grant \#634413) are acknowledged.

\section{Reference List}

1. Anjani,K, Lhomme,M, Sokolovska,N, Poitou,C, Aron-Wisnewsky,J, Bouillot,JL, Lesnik,P, Bedossa,P, Kontush,A, Clement,K, Dugail,I, Tordjman,J: Circulating phospholipid profiling identifies portal contribution to NASH signature in obesity. $J$ Hepatol 62:905-912, 2015

2. Meikle,PJ, Wong,G, Barlow,CK, Weir,JM, Greeve,MA, MacIntosh,GL, Almasy,L, Comuzzie,AG, Mahaney,MC, Kowalczyk,A, Haviv,I, Grantham,N, Magliano,DJ, Jowett,JB, Zimmet,P, Curran,JE, Blangero,J, Shaw,J: Plasma lipid profiling shows similar associations with prediabetes and type 2 diabetes. PLoS ONE 8:e74341, 2013

3. Yang,L, Cui,X, Zhang,N, Li,M, Bai,Y, Han,X, Shi,Y, Liu,H: Comprehensive lipid profiling of plasma in patients with benign breast tumor and breast cancer reveals novel biomarkers. Anal Bioanal Chem 407:5065-5077, 2015

4. Ivanova,PT, Milne,SB, Byrne,MO, Xiang,Y, Brown,HA: Glycerophospholipid identification and quantitation by electrospray ionization mass spectrometry. Methods Enzymol 432:21-57, 2007

5. Barroso,B, Bischoff,R: LC-MS analysis of phospholipids and lysophospholipids in human bronchoalveolar lavage fluid. J Chromatogr B Analyt Technol Biomed Life Sci $814: 21-28,2005$ 
6. Cifkova,E, Holcapek,M, Lisa,M, Vrana,D, Melichar,B, Student,V: Lipidomic differentiation between human kidney tumors and surrounding normal tissues using HILIC-HPLC/ESI-MS and multivariate data analysis. J Chromatogr B Analyt Technol Biomed Life Sci 1000:14-21, 2015

7. Meikle,PJ, Duplock,S, Blacklock,D, Whitfield,PD, Macintosh,G, Hopwood,JJ, Fuller,M: Effect of lysosomal storage on bis(monoacylglycero)phosphate. Biochem J 411:71-78, 2008

8. KANFER,J, KENNEDY,EP: METABOLISM AND FUNCTION OF BACTERIAL LIPIDS. II. BIOSYNTHESIS OF PHOSPHOLIPIDS IN ESCHERICHIA COLI. J Biol Chem 239:1720-1726, 1964

9. KIYASU,JY, PIERINGER,RA, PAULUS,H, KENNEDY,EP: The biosynthesis of phosphatidylglycerol. J Biol Chem 238:2293-2298, 1963

10. Miyazaki,C, Kuroda,M, Ohta,A, Shibuya,I: Genetic manipulation of membrane phospholipid composition in Escherichia coli: pgsA mutants defective in phosphatidylglycerol synthesis. Proc Natl Acad Sci U S A 82:7530-7534, 1985

11. Nishijima,M, Raetz,CR: Membrane lipid biogenesis in Escherichia coli: identification of genetic loci for phosphatidylglycerophosphate synthetase and construction of mutants lacking phosphatidylglycerol. J Biol Chem 254:7837-7844, 1979

12. Chang,SC, Heacock,PN, Clancey,CJ, Dowhan,W: The PEL1 gene (renamed PGS1) encodes the phosphatidylglycero-phosphate synthase of Saccharomyces cerevisiae. $J$ Biol Chem 273:9829-9836, 1998

13. Kawasaki,K, Kuge,O, Chang,SC, Heacock,PN, Rho,M, Suzuki,K, Nishijima,M, Dowhan,W: Isolation of a chinese hamster ovary (CHO) cDNA encoding phosphatidylglycerophosphate (PGP) synthase, expression of which corrects the mitochondrial abnormalities of a PGP synthase-defective mutant of CHO-K1 cells. $J$ Biol Chem 274:1828-1834, 1999

14. Lu,YH, Guan,Z, Zhao,J, Raetz,CR: Three phosphatidylglycerol-phosphate phosphatases in the inner membrane of Escherichia coli. J Biol Chem 286:5506-5518, 2011

15. Zhang,J, Guan,Z, Murphy,AN, Wiley,SE, Perkins,GA, Worby,CA, Engel,JL, Heacock,P, Nguyen,OK, Wang,JH, Raetz,CR, Dowhan,W, Dixon,JE: Mitochondrial phosphatase PTPMT1 is essential for cardiolipin biosynthesis. Cell Metab 13:690-700, 2011

16. Osman,C, Haag,M, Wieland,FT, Brugger,B, Langer,T: A mitochondrial phosphatase required for cardiolipin biosynthesis: the PGP phosphatase Gep4. EMBO J 29:19761987, 2010

17. Kelly,BL, Greenberg,ML: Characterization and regulation of phosphatidylglycerolphosphate phosphatase in Saccharomyces cerevisiae. Biochim Biophys Acta 1046:144-150, 1990

18. Xia,W, Dowhan,W: Phosphatidylinositol cannot substitute for phosphatidylglycerol in supporting cell growth of Escherichia coli. J Bacteriol 177:2926-2928, 1995

19. Kikuchi,S, Shibuya,I, Matsumoto,K: Viability of an Escherichia coli pgsA null mutant lacking detectable phosphatidylglycerol and cardiolipin. J Bacteriol 182:371-376, 2000

20. Matsumoto,K: Dispensable nature of phosphatidylglycerol in Escherichia coli: dual roles of anionic phospholipids. Mol Microbiol 39:1427-1433, 2001

21. Hashimoto,M, Takahashi,H, Hara,Y, Hara,H, Asai,K, Sadaie, Y, Matsumoto,K: Induction of extracytoplasmic function sigma factors in Bacillus subtilis cells with membranes of reduced phosphatidylglycerol content. Genes Genet Syst 84:191-198, 2009

22. den Kamp,JA, Redai,I, van Deenen,LL: Phospholipid composition of Bacillus subtilis. $J$ Bacteriol 99:298-303, 1969 
23. Hostetler,KY, van den Bosch,H: Subcellular and submitochondrial localization of the biosynthesis of cardiolipin and related phospholipids in rat liver. Biochim Biophys Acta 260:380-386, 1972

24. Hirschberg,CB, KENNEDY,EP: Mechanism of the enzymatic synthesis of cardiolipin in Escherichia coli. Proc Natl Acad Sci U S A 69:648-651, 1972

25. Tan,BK, Bogdanov,M, Zhao,J, Dowhan,W, Raetz,CR, Guan,Z: Discovery of a cardiolipin synthase utilizing phosphatidylethanolamine and phosphatidylglycerol as substrates. Proc Natl Acad Sci U S A 109:16504-16509, 2012

26. Li,C, Tan,BK, Zhao,J, Guan,Z: In vivo and in vitro synthesis of phosphatidylglycerol by an Escherichia coli cardiolipin synthase. J Biol Chem 2016

27. Burritt,MF, Henderson,TO: Properties of a membrane-bound cardiolipin synthetase from Lactobacillus plantarum. J Bacteriol 123:972-977, 1975

28. Short,SA, White,DC: Biosynthesis of cardiolipin from phosphatidylglycerol in Staphylococcus aureus. J Bacteriol 109:820-826, 1972

29. Hostetler,KY, van den Bosch,H, van Deenen,LL: The mechanism of cardiolipin biosynthesis in liver mitochondria. Biochim Biophys Acta 260:507-513, 1972

30. Tsai,M, Ohniwa,RL, Kato,Y, Takeshita,SL, Ohta,T, Saito,S, Hayashi,H, Morikawa,K: Staphylococcus aureus requires cardiolipin for survival under conditions of high salinity. BMC Microbiol 11:13, 2011

31. Hullin-Matsuda,F, Kawasaki,K, Delton-Vandenbroucke,I, Xu,Y, Nishijima,M, Lagarde,M, Schlame,M, Kobayashi,T: De novo biosynthesis of the late endosome lipid, bis(monoacylglycero)phosphate. J Lipid Res 48:1997-2008, 2007

32. Gallala,HD, Sandhoff,K: Biological function of the cellular lipid BMP-BMP as a key activator for cholesterol sorting and membrane digestion. Neurochem Res 36:15941600, 2011

33. Roy,H: Tuning the properties of the bacterial membrane with aminoacylated phosphatidylglycerol. IUBMB Life 61:940-953, 2009

34. Smith,AM, Harrison,JS, Sprague,KM, Roy,H: A conserved hydrolase responsible for the cleavage of aminoacylphosphatidylglycerol in the membrane of Enterococcus faecium. J Biol Chem 288:22768-22776, 2013

35. Bogdanov, M, Dowhan,W, Vitrac,H: Lipids and topological rules governing membrane protein assembly. Biochim Biophys Acta 1843:1475-1488, 2014

36. Zhao,W, Rog,T, Gurtovenko,AA, Vattulainen,I, Karttunen,M: Role of phosphatidylglycerols in the stability of bacterial membranes. Biochimie 90:930-938, 2008

37. Simons,K, Toomre,D: Lipids rafts in cells membranes. Nature Reviews Molecular Cell Biology 1:31-39, 2000

38. Mileykovskaya,E, Dowhan,W: Cardiolipin membrane domains in prokaryotes and eukaryotes. Biochim Biophys Acta 1788:2084-2091, 2009

39. Matsumoto,K, Hara,H, Fishov,I, Mileykovskaya,E, Norris,V: The membrane: transertion as an organizing principle in membrane heterogeneity. Front Microbiol 6:572, 2015

40. Pugsley,AP: The complete general secretory pathway in gram-negative bacteria. Microbiol Rev 57:50-108, 1993

41. Shiba,Y, Yokoyama,Y, Aono,Y, Kiuchi,T, Kusaka,J, Matsumoto,K, Hara,H: Activation of the Rcs signal transduction system is responsible for the thermosensitive growth defect of an Escherichia coli mutant lacking phosphatidylglycerol and cardiolipin. $J$ Bacteriol 186:6526-6535, 2004 
42. Narita,Si, Tokuda,H: Bacterial lipoproteins; biogenesis, sorting and quality control. Biochimica et Biophysica Acta (BBA) - Molecular and Cell Biology of Lipids S13881981:30323-30327, 2016

43. Jerga, A, Lu,YJ, Schujman,GE, de,MD, Rock,CO: Identification of a soluble diacylglycerol kinase required for lipoteichoic acid production in Bacillus subtilis. $J$ Biol Chem 282:21738-21745, 2007

44. Helmann,JD: The extracytoplasmic function (ECF) sigma factors. Adv Microb Physiol 46:47-110, 2002

45. Hashimoto,M, Takahashi,H, Hara,Y, Hara,H, Asai,K, Sadaie,Y, Matsumoto,K: Induction of extracytoplasmic function sigma factors in Bacillus subtilis cells with membranes of reduced phosphatidylglycerol content. Genes Genet Syst 84:191-198, 2009

46. Wada,H, Murata,N: The essential role of phosphatidylglycerol in photosynthesis. Photosynth Res 92:205-215, 2007

47. Shinzawa-Itoh,K, Aoyama,H, Muramoto,K, Terada,H, Kurauchi,T, Tadehara,Y, Yamasaki,A, Sugimura,T, Kurono,S, Tsujimoto,K, Mizushima,T, Yamashita,E, Tsukihara,T, Yoshikawa,S: Structures and physiological roles of 13 integral lipids of bovine heart cytochrome c oxidase. EMBO J 26:1713-1725, 2007

48. Zhu,SQ, Zhao,H, Liang,JS, Ji,BH, Jiao,DM: Relationships between phosphatidylglycerol molecular species of thylakoid membrane lipids and sensitivities to chilling-induced photoinhibition in rice. J Integr Plant Biol 50:194-202, 2008

49. Kruse,O, Hankamer,B, Konczak,C, Gerle,C, Morris,E, Radunz,A, Schmid,GH, Barber,J: Phosphatidylglycerol is involved in the dimerization of photosystem II. J Biol Chem 275:6509-6514, 2000

50. Sakurai,I, Mizusawa,N, Ohashi,S, Kobayashi,M, Wada,H: Effects of the lack of phosphatidylglycerol on the donor side of photosystem II. Plant Physiol 144:1336-1346, 2007

51. Goerke,J: Pulmonary surfactant: functions and molecular composition. Biochimica et Biophysica Acta (BBA) - Molecular Basis of Disease 1408:79-89, 1998

52. Postle,AD, Heeley,EL, Wilton,DC: A comparison of the molecular species compositions of mammalian lung surfactant phospholipids. Comp Biochem Physiol A Mol Integr Physiol 129:65-73, 2001

53. Bates,SR, Dodia,C, Tao,JQ, Fisher,AB: Surfactant protein-A plays an important role in lung surfactant clearance: evidence using the surfactant protein-A gene-targeted mouse. Am J Physiol Lung Cell Mol Physiol 294:L325-L333, 2008

54. Beinlich,A, Fischass,C, Kaufmann,M, Schlosser,R, Dericks-Tan,JS: Lamellar body counts in amniotic fluid for prediction of fetal lung maturity. Arch Gynecol Obstet 262:173-180, 1999

55. Crouch,EC: Collectins and pulmonary host defense. Am J Respir Cell Mol Biol 19:177201, 1998

56. Wright,JR: Immunomodulatory functions of surfactant. Physiol Rev 77:931-962, 1997

57. Hite,RD, Seeds,MC, Bowton,DL, Grier,BL, Safta,AM, Balkrishnan,R, Waite,BM, Bass,DA: Surfactant phospholipid changes after antigen challenge: a role for phosphatidylglycerol in dysfunction. Am J Physiol Lung Cell Mol Physiol 288:L610L617, 2005

58. Numata,M, Chu,HW, Dakhama,A, Voelker,DR: Pulmonary surfactant phosphatidylglycerol inhibits respiratory syncytial virus-induced inflammation and infection. Proc Natl Acad Sci U S A 107:320-325, 2010

59. Kuronuma,K, Mitsuzawa,H, Takeda,K, Nishitani,C, Chan,ED, Kuroki,Y, Nakamura,M, Voelker,DR: Anionic pulmonary surfactant phospholipids inhibit inflammatory 
responses from alveolar macrophages and U937 cells by binding the lipopolysaccharideinteracting proteins CD14 and MD-2. J Biol Chem 284:25488-25500, 2009

60. Dijkman,PM, Watts,A: Lipid modulation of early $\mathrm{G}$ protein-coupled receptor signalling events. Biochimica et Biophysica Acta (BBA) - Biomembranes 1848:2889-2897, 2015

\section{Figure legends}

Figure 1: Specific roles of PGs across organisms.

The developped formula of PG in the center does not indicate the 2-position of glycerol which is a chiral center. Note that this position is sn-glycerol-1-P in contrast to the backbone, which is sn-glycerol-3-P.

Figure 2: Fatty acid diversity in PGs.

Each circle indicates relative concentrations of PGs (Log scale) quantified by LC/MS in different samples from mammals or microbes as indicated. First number in parenthesis indicates total number of carbons in fatty acid chains, the second is the total number of insaturations in lipid chains. Note that in bacteria odd chains fatty acids corresponding to branched chains are found.

Figure 3: Schematic overview of PG synthesis pathway.

Abbreviations are as follows: CDP-DAG, cytidine diphosphate diacylglycerol. PGP, Phosphatidylglycerol-phosphate. CL, Cardiolipin. PS, Phosphatidylserine. PE

Phosphatidylethanolamine. Enzymatic activities (not gene names) are indicated in each step. 


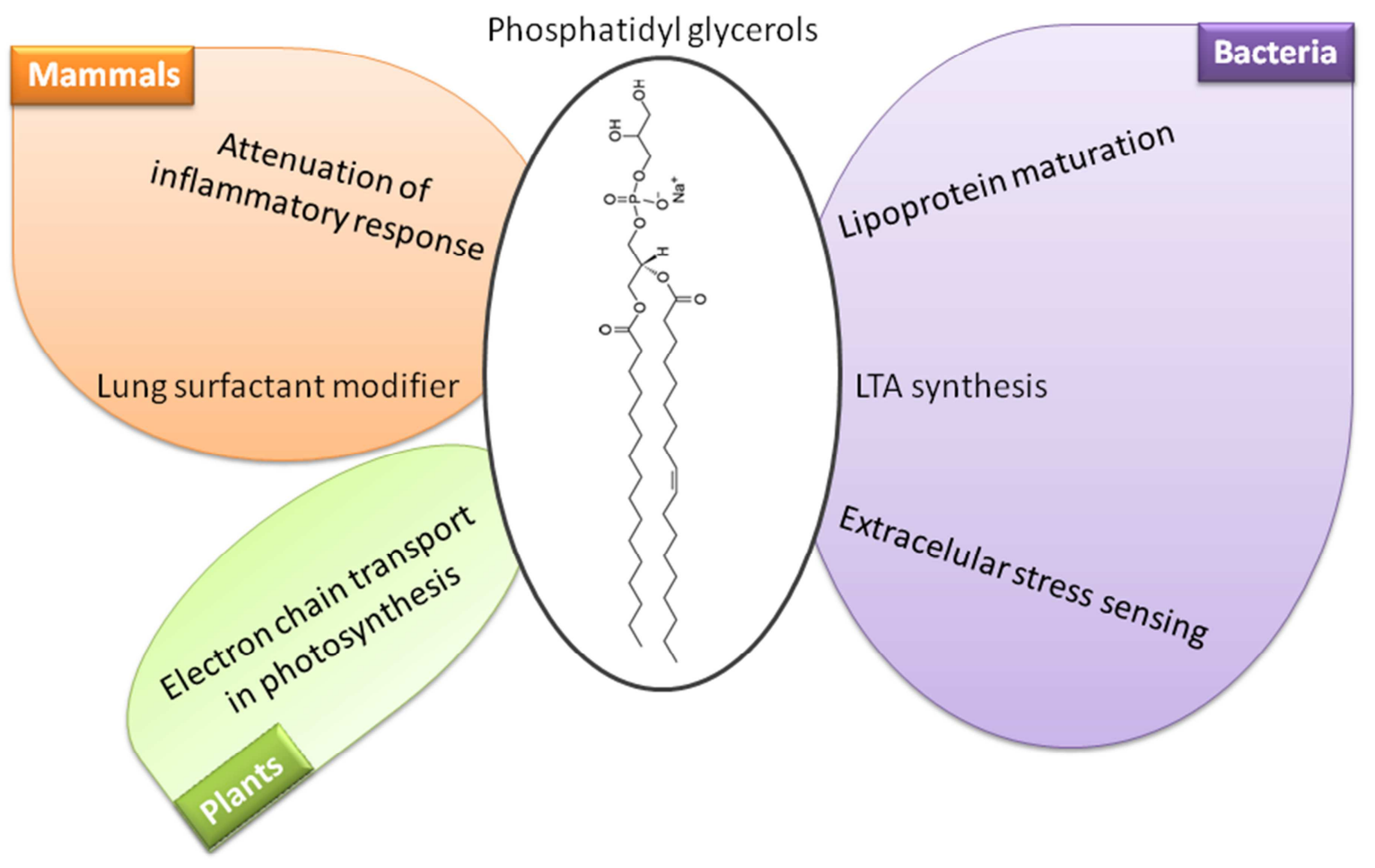

Figure 1 
C57BI6 mice serum (regular diet)

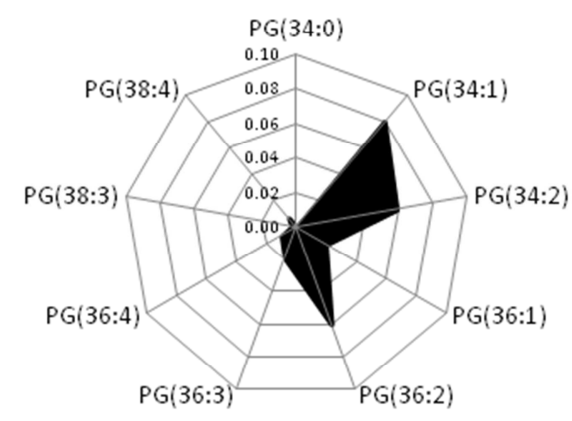

Lactobacillus Bifidus

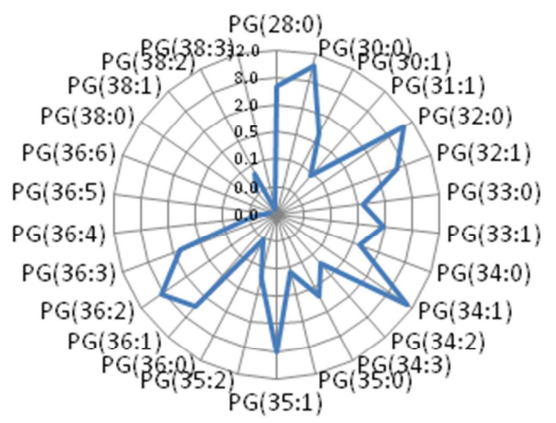

Human serum (Obese patients)

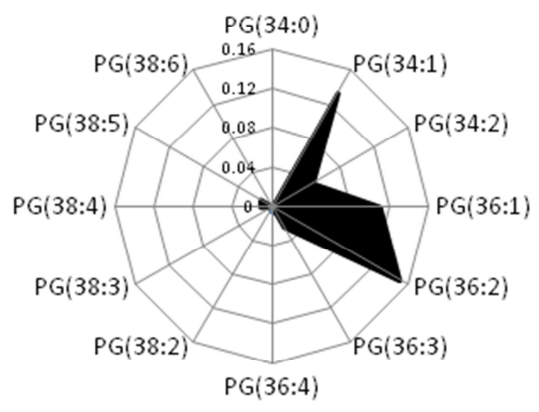

\section{Lactobacillus Casei}

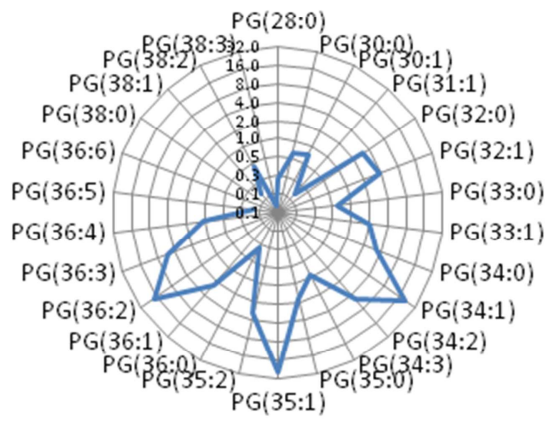

Figure 2 


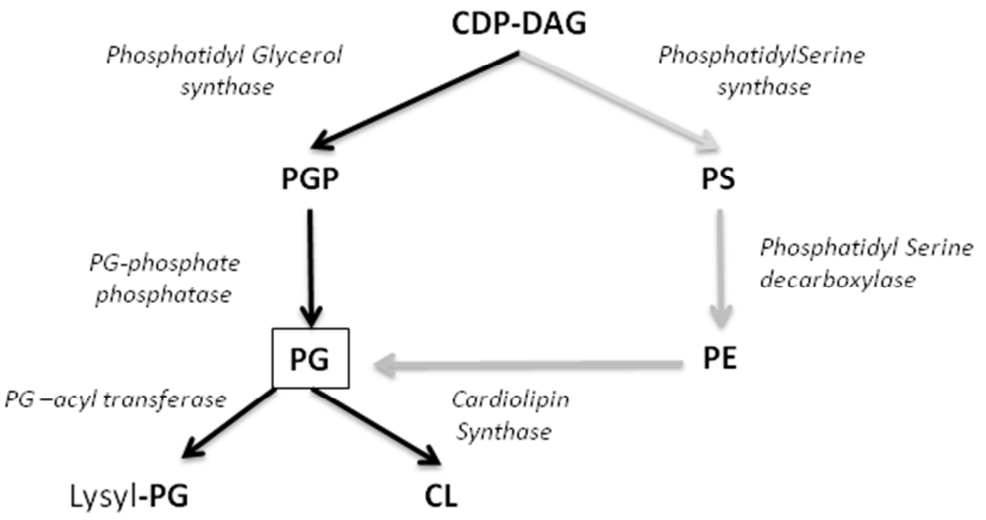

Figure 3 


\section{Highlights:}

-Common schemes in PG synthesis exist in eukariotes and microbes

-High PG in bacterial membranes is reflected by a mitochondria-specific distribution.

-PG functions cover lipid/protein interactions, electron transport and regulation of bilayer tension

-New roles may emerge due to development of lipidomics by mass spectrometry. 